\title{
THE ELECTROCARDIOGRAM IN SYPHILITIC HEART DISEASE
}

\author{
BY \\ GEOFFREY STOREY \\ From the Cardiac Department of the London Hospital
}

Received October 31, 1957

The greater incidence of syphilitic heart disease is in late acquired syphilis and there is no evidence that the heart is involved during the early stage of the infection, though this is less certain in congenital syphilis. The aortitis of late acquired syphilis usually starts above the aortic valve and may spread upwards, producing weakness of the wall of the aorta and resulting in aneurysm formation; aortic incompetence may then result from stretching of the aortic ring. The syphilitic process, however, more commonly spreads down to involve the aortic cusps, producing aortic incompetence from valvitis. In either case the orifices of the coronary vessels may be narrowed (although this does not often occur in the presence of aneurysm alone).

Abnormalities of the electrocardiogram result from left ventricular hypertrophy following aortic incompetence or as a result of cardiac ischæmia from stenosis of the coronary orifices. Whether the heart itself is commonly involved by an inflammatory lesion has been much discussed; certainly gummata of the heart occur, either as a single gumma or as a diffuse infiltration, but are rare. Opinion still varies as to whether the patchy fibrosis found in the myocardium is caused by stenosis of the coronary orifices or by syphilitic myocarditis, but the former explanation is now the most favoured.

There is no agreement on the importance of the electrocardiogram in the diagnosis of stenosis of the coronary orifices and this work was undertaken to investigate this problem.

In congenital syphilis it is clear from the reports of various authors that although the Treponema pallida is found in the heart there is no reaction to it by the tissue. Similarly several reports are available on the findings in early adult syphilis and most authors (Turner and White, 1927; Ingraham and Maynard, 1930; Chamberlain and Follows, 1933; Annett, 1928) agree that there are no certain electrocardiographic abnormalities. More recently Klotz and Crede (1945) found only four cases among 100 cases of early syphilis with some abnormality of the $T$ waves.

In late syphilis, abnormalities of the cardiogram have been frequently described, but the criteria of such abnormalities are not now acceptable. Thus, the differentiation of ischæmic changes from left ventricular preponderance was not then made, while left ventricular preponderance was often inferred from left axis deviation only. Other abnormalities that have been described are auriculo-ventricular dissociation, bundle-branch block, and slurring of the QRS.

Heimann (1927) described notching of the $R$ wave in limb leads which he believed was specific of syphilitic heart disease. The specificity of the notch has not been confirmed by later writers although slurring and notching of the QRS is often described, and Evans and McRae (1952) believe that notching of the QRS in CR7, even in the presence of left ventricular preponderance, signifies ischæmia.

Juster and Pardee (1929) were the first to relate cardiographic abnormalities to ostial stenosis, and reported $T$ wave changes that they attributed to this in 18 per cent of their cases; they correlated these with post-mortem findings. Coombs (1932), reviewing the subject, collected the findings in 276 cases, and noted the divergent opinions expressed by the various authors and concluded that the cardiogram was of little value in the diagnosis of coronary orifice occlusion. Several authors have agreed with this. Bruenn (1934) reported no difference between the cardiogram in cases with much stenosis of the coronary orifices and those with little or no stenosis. Smith and Blackford (1938) found little difference between the cardiogram in cases with and those without pain in the chest, while Burch and Winsor (1942) agreed with this. 
It should be appreciated, however, that chest lead electrocardiography was only in its infancy then. Sprague (1942), describing 22 cases of syphilitic heart disease examined at necropsy, found narrowing of the ostia in three out of four cases of bundle-branch block. He also drew attention to the fact that atheroma of the coronary arteries might be co-existent with syphilitic heart disease, as already noted by Gallavardin (1932), and might be responsible for abnormalities in the cardiogram.

Most authors agree that stenosis of the coronary orifices rarely causes a large area of cardiac infarction. Parsonnet and Bernstein (1943) and Jones and Bedford (1943) comment on the rarity of the finding of $Q$ waves in syphilitic heart disease.

The introduction of the exercise test is a further aid in the recognition of coronary ostial stenosis, and Berk (1941) found it valuable, particularly in syphilitic patients under 45 years of age, where coronary atheroma was less likely to be a complicating factor.

Apart from the effects of cardiac ischæmia and hypertrophy of the left ventricle, cardiographic abnormalities may occur rarely from the presence of gummata in the myocardium; these may take the form of a single gumma or a diffuse gummatous infiltration. The cardiographic abnormalities take the form of a conduction defect with alteration in rhythm.

In recent years much attention has been paid to the various types of cardiographic patterns produced by interference with the blood supply to the myocardium. Master et al. (1944) have differentiated a syndrome of coronary insufficiency from that of cardiac infarction. This is characterized by $\mathrm{S}-\mathrm{T}$ depression or $\mathrm{T}$ wave inversion without $\mathrm{Q}$ waves or $\mathrm{S}-\mathrm{T}$ elevation. They mention stenosis of the coronary orifices from syphilis as a cause of this syndrome. The electrocardiographic changes may be transient, and they attribute the $\mathbf{S}-\mathbf{T}$ depression to the subendocardial localization of the lesion. Yu and Stewart (1950) have supported this view. Levine and Ford (1950) believe that the subendocardial region is the most likely to suffer in any condition that causes depression of the total coronary flow, and Evans and McRae (1952) have described various lesser changes in the $\mathrm{S}-\mathrm{T}$ and $\mathrm{T}$ wave that indicate such coronary arterial interruption.

\section{MATERIAL AND MeThOD}

Seventy-two patients were examined. They were admitted to the series if they showed aortic incompetence in the absence of mitral stenosis and had a positive Wassermann reaction, or if they were found to have an aortic aneurism with or without a positive Wassermann reaction. The early diastolic murmur of aortic incompetence varied from soft and blowing to loud and rough, and was sometimes accompanied by a thrill. A systolic murmur was usually present as well.

The clinical signs of aneurysm were sought, but reliance was placed on radiology for its diagnosis. Care was taken to exclude the presence of rheumatic valvular disease. Auscultation to elicit a mid-diastolic murmur in the mitral area, with the addition of phonocardiography in doubtful cases, and cardioscopy during a barium swallow to exclude an enlargement of the left atrium, were the methods employed to prove the absence of mitral stenosis. Cases with doubtful dilatation of the aorta were not included. Enlargement of the left ventricle was sought, and in some cases it was surprisingly slight in the presence of long standing aortic valve disease.

Calcification of the aortic valve was looked for, especially when the systolic murmur was very rough. As only 5 of the 72 were examined at necropsy the records of the Bernhard Baron Institute of Pathology for the years 1922 to 1948 were examined to ascertain the customary pathological changes in like cases.

A history of primary luetic infection was often missing. The two common symptoms were pain in the chest and shortness of breath. Special attention was paid to pain, and having regard to its character the cases were placed in three groups. In the first there were 34 who appeared historically to have true cardiac pain; in the second there were 21 cases where the pain was somewhat atypical of cardiac pain; and in the third group 17 cases where pain was absent.

The electrocardiogram will be described in relation to these three groups (Table I). The routine 'leads taken were the conventional limb leads I, II, and III and chest leads CR1, CR4, and CR7. In special cases other leads were taken, and in some where the electrocardiogram was normal or nearly normal in the presence of pain, the exercise test was added. The two step test was used, and the exercise test was continued for three minutes unless pain in the chest had set in. The 
electrocardiogram was then recorded immediately, and at intervals of three, five, and fifteen minutes. A positive test was assumed to be present when significant $\mathbf{S}-\mathrm{T}$ depression took place. This was usually seen best in leads CR4 or CR7. The electrocardiographic findings in the three groups of cases will now be described.

TABLE I

The Electrocardiogram in 72 Patients with Syphilitic Heart Disease

\begin{tabular}{|c|c|c|c|c|c|c|c|c|}
\hline \multirow[b]{2}{*}{$\begin{array}{l}\text { Clinical } \\
\text { classification }\end{array}$} & \multirow[b]{2}{*}{$\begin{array}{l}\text { Aortic in- } \\
\text { competence }\end{array}$} & \multirow[b]{2}{*}{$\begin{array}{l}\text { Normal } \\
\text { cardiogram }\end{array}$} & \multicolumn{6}{|c|}{ Abnormal cardiogram } \\
\hline & & & $\begin{array}{l}\text { Ischæmic } \\
\text { effects }\end{array}$ & L.V.P. & $\begin{array}{l}\text { L.V.P. and } \\
\text { ischæmic } \\
\text { effects }\end{array}$ & B.B.B. & $\begin{array}{l}\text { A-V con- } \\
\text { duction } \\
\text { defect }\end{array}$ & A.F. \\
\hline \multirow{2}{*}{$\underset{(34)}{\text { Cardiac pain }}$} & $\begin{array}{c}(4) \\
\text { Absent }\end{array}$ & - & 4 & - & - & - & - & - \\
\hline & $\begin{array}{c}(30) \\
\text { Present }\end{array}$ & 1 & 15 & 8 & 6 & 2 & - & - \\
\hline \multirow{2}{*}{$\begin{array}{l}\text { Non-cardiac } \\
\text { pain } \\
\text { (21) }\end{array}$} & $\begin{array}{c}\text { (6) } \\
\text { Absent }\end{array}$ & 5 & - & - & - & - & 1 & - \\
\hline & $\begin{array}{c}(15) \\
\text { Present }\end{array}$ & 6 & - & 8 & - & 1 & 2 & 1 \\
\hline \multirow{2}{*}{$\begin{array}{l}\text { No pain } \\
\text { (17) }\end{array}$} & $\begin{array}{c}(5) \\
\text { Absent }\end{array}$ & 5 & - & - & - & - & - & - \\
\hline & $\begin{array}{c}\text { (12) } \\
\text { Present }\end{array}$ & 5 & - & 5 & - & 1 & - & 3 \\
\hline
\end{tabular}

Numerals indicate number of cases. Cases may appear in more than one column.

B.B.B.= Bundle-branch block.

L.V.P. = Left ventricular preponderance.

A.F.=Auricular fibrillation.

\section{RESULTS}

Ischamic Changes. Cardiograms showing ischæmic changes were divided into two groups. The first where they predominated, and the second where they were present alongside left ventricular preponderance. In the first group were 19 cases, and in the second, 6 cases.

In the first group, abnormal $\mathrm{Q}$ waves were present in only two cases and Pardee sign only once, so that reliance had to be placed on $\mathrm{S}-\mathrm{T}$ and $\mathrm{T}$ wave changes as an index of myocardial changes. Reliance was placed on a changing cardiogram, on $\mathrm{T}$ wave inversion atypical of left ventricular preponderance, on the lesser cardiographic changes described by Evans and McRae (1952), and on the exercise electrocardiogram.

A changing cardiogram, in the absence of other complications like arrhythmia or digitalis therapy, may be accepted as evidence of ischæmic effects. Nine cases came into this group, seven with incompetence and two without. Five cases each with aortic incompetence, showed different degrees of inversion of $\mathrm{T}$ waves. One showed $\mathrm{S}-\mathrm{T}$ elevation and $\mathrm{T}$ wave inversion in leads II and III at one time, and later the T wave became upright in lead II and later still, inverted in leads II and III. Another showed left ventricular preponderance with S-T depression and T wave inversion in leads I, II, and CR7, while later the T waves moved upright in these leads (Fig. 1). Another showed transient inversion of the T waves in leads I, CR4, and CR7, and later these became upright in leads CR4 and CR7 (Fig. 2). Another showed a pattern suggestive of left ventricular 


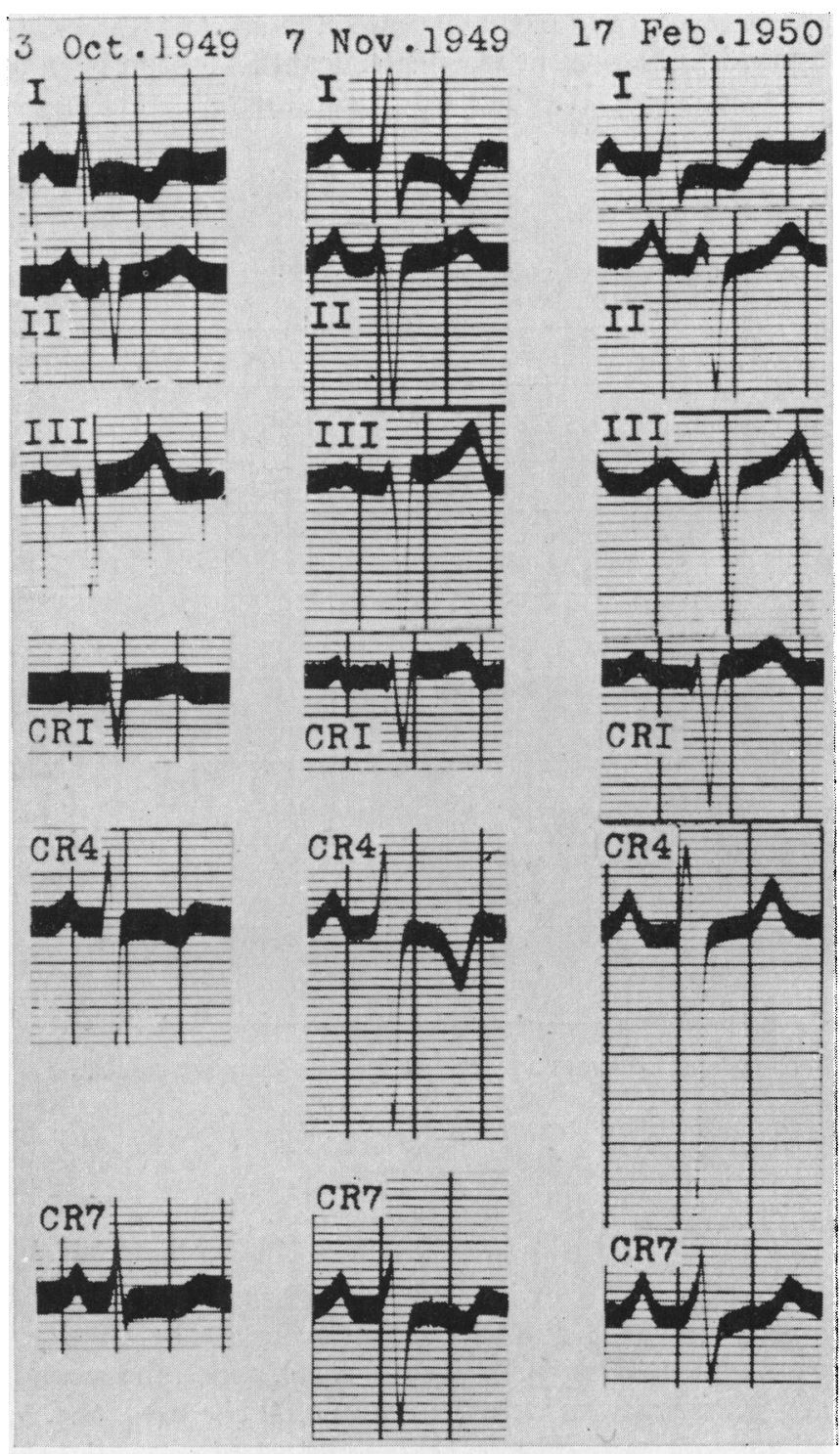

FIG. 1.-Varying inversion of $\mathrm{T}$ waves in lead I, CR4, and CR7.

preponderance at first, but later developed deep $T$ wave inversion in lead CR4, deeper than in CR7, and thereafter the T waves in leads I, II, CR4, and CR7 then became flat or bifid and once more inverted.

The remaining four cases with fluctuating changes showed less deformities of the S-T segment, or flattening of the $T$ waves. One showed transient S-T depression in leads I, CR4, and CR7. This type of change may be seen during an attack of anginal pain (Hall, 1932; Parkinson and Bedford, 1931), although this patient did not have such an attack while the tracing was being taken. The second showed low $T$ waves in leads I and CR7, with a bifid T in CR4, which later became taller. A notch was present in the QRS in CR7 as an additional significant abnormality. The third showed a similar change, with a transient low T wave in lead I, S-T depression in CR7, and 


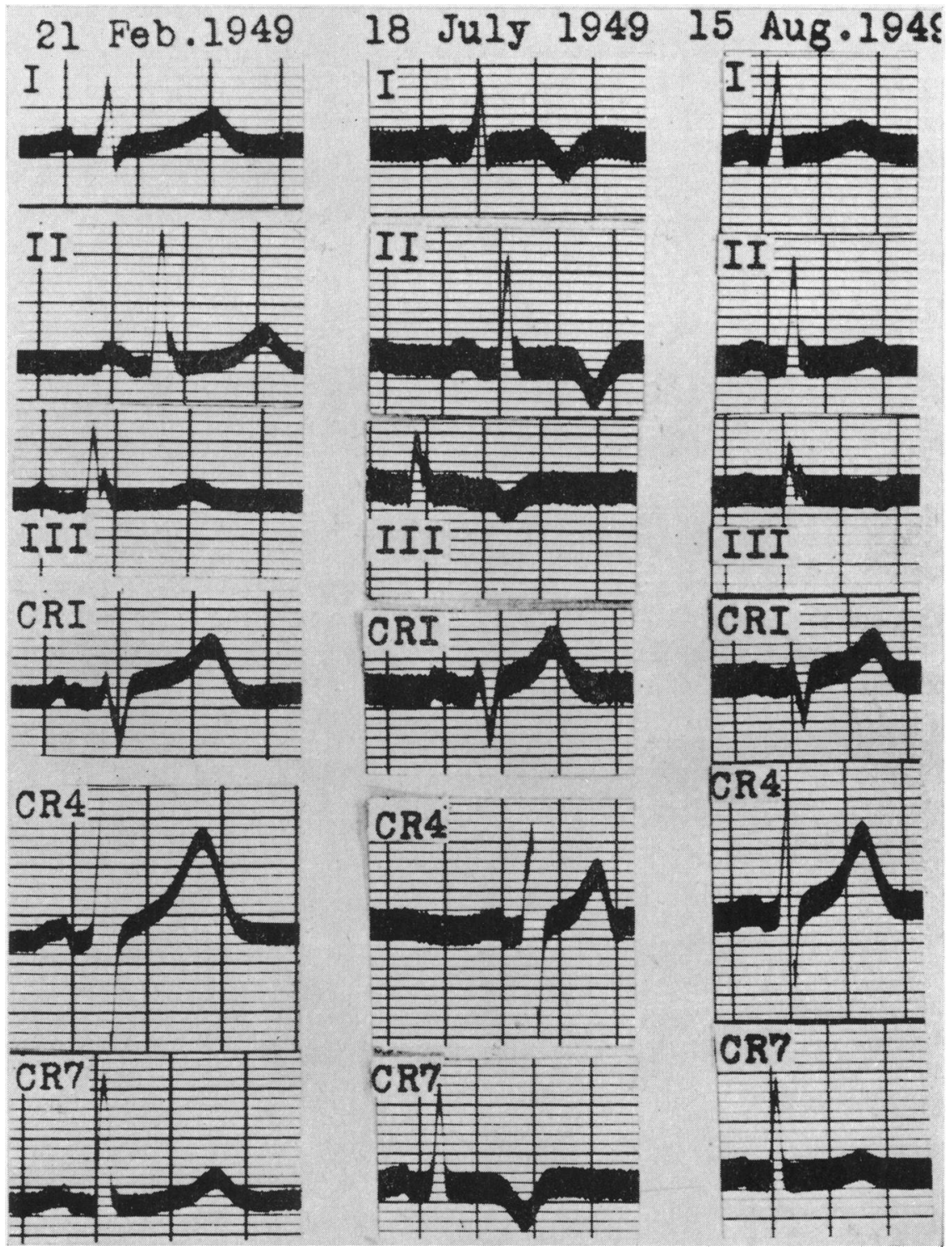

FIG. 2.-Transient inversion of $\mathrm{T}$ waves in leads I, II, and CR7.

a bifid T wave in CR4, and the fourth showed a flat T wave in leads I and CR7 on one occasion which later became upright. This patient died as the result of a rupture of an aortic aneurysm, and post mortem showed that the myocardial ischæmia had probably resulted from atheroma rather than obstruction of the coronary orifices by syphilitic aortitis.

$T$ wave inversion not typical of left ventricular preponderance, usually affected leads II and III for although left ventricular preponderance of aortic valve disease may sometimes show as S-T and T wave changes in leads II, III, and CR7 (Evans, 1948), if the QRS is not tall in lead CR7 it is likely to be the outcome of a myocardial injury. Five cases showed these abnormalities. In one of these the S-T depression and T wave inversion in leads II and III suggested left ventricular preponderance, but the chest leads showed no evidence of this. 


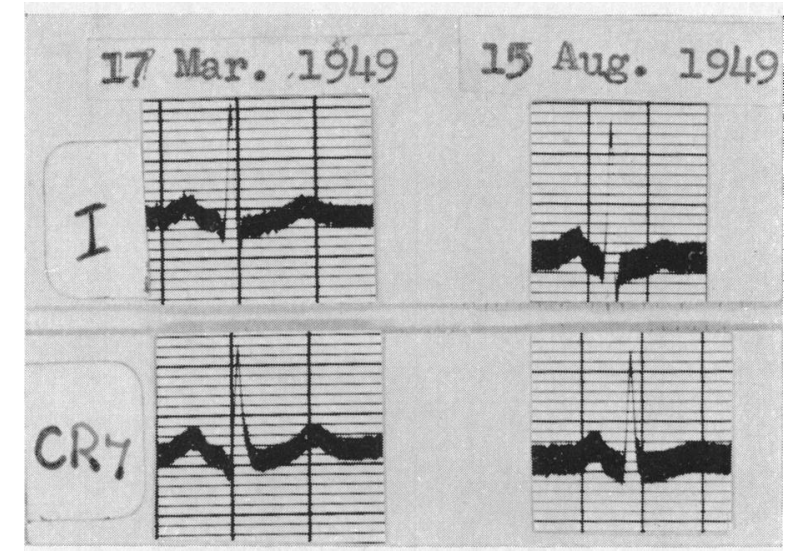

- FIG. 3.-Flattening of the $T$ waves in lead $I$ and $C R 7$ in the absence of aortic incompetence.

Lesser Changes. These were seen in four cases. One of these had S-T depression in leads I, CR4, and CR7, and the other S-T depression in lead I. The third showed S-T depression and flat $T$ waves in leads $I$ and CR7 in the absence of aortic incompetence (Fig. 3). Two of them had a positive exercise test.

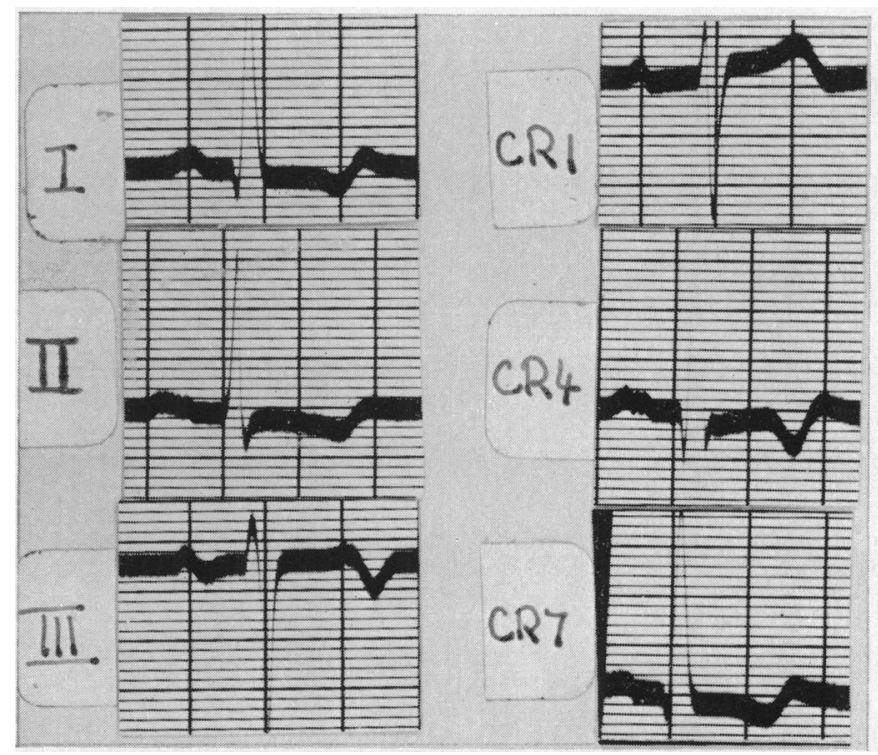

FIG. 4. - T wave inversion in lead CR4, deeper than in CR7, suggesting ischæmia.

\section{Left Ventricular Preponderance Conjoined with Ischamic Effects}

In the presence of left ventricular preponderance, ischæmic changes are often difficult to recognize. Should the T wave in leads I or CR4 be deeper than CR7 a myocardial injury is likely to be present (Evans, 1948). Three cases showed this as a lasting feature (Fig. 4) and another as a transient sign confirming the ischæmic nature of the abnormality. 


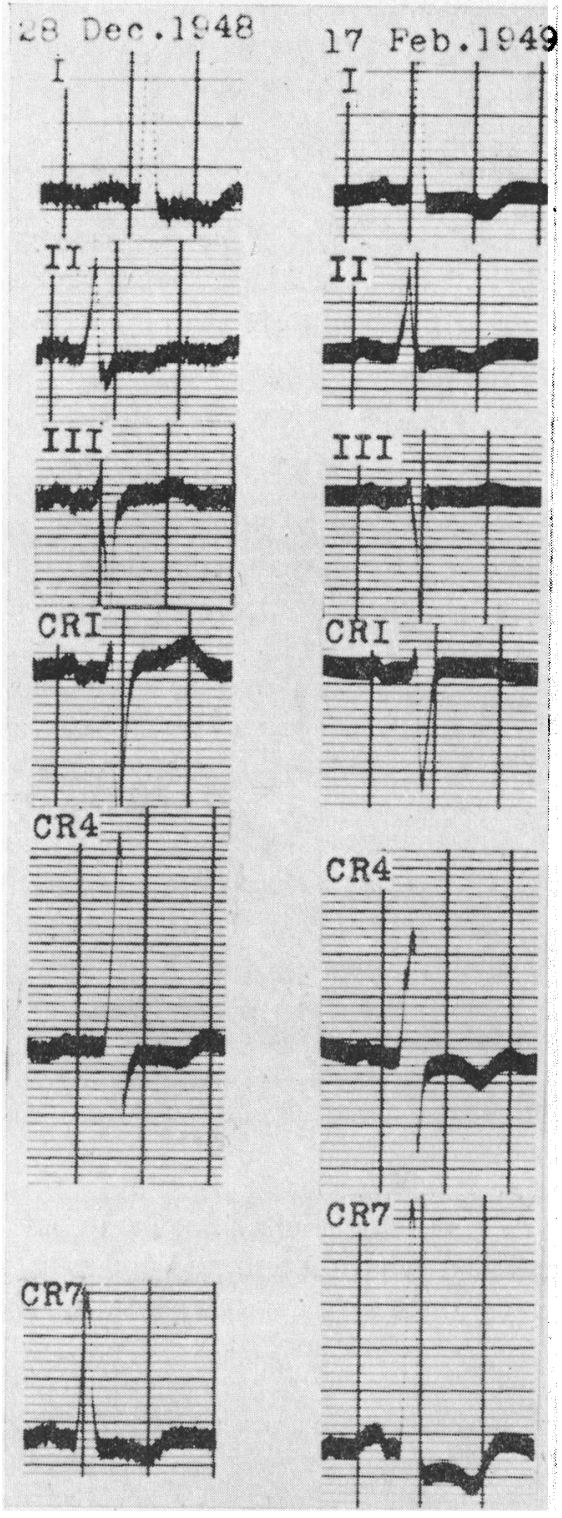

Fig. 5.-Left ventricular preponderance, but later upward bowing of the S-T segment in CR4 suggesting ischæmia.

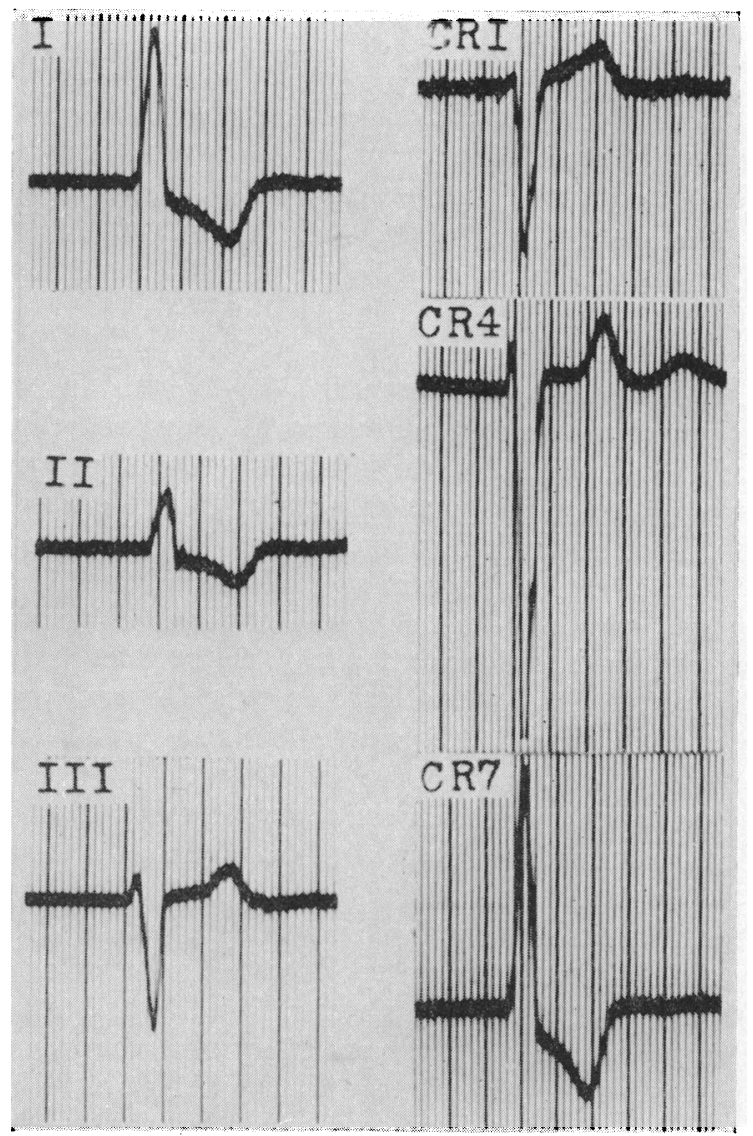

Fig. 6.-Left ventricular preponderance, but with a flattening of the $\mathrm{S}-\mathrm{T}$ segment in lead CR4. Necropsy showed stenosis of the coronary orifices.

Again, alteration in the shape of the S-T segment in CR4 with upward bowing gave support to the diagnosis, and three patients showed this feature (Fig. 5). One of them died and necropsy showed great stenosis of both coronary orifices and ischæmic changes in the myocardium.

\section{Left Ventricular Preponderance}

Twenty-one cases showed this change. Twenty of them showed the usual pattern of left ventricular preponderance, namely, S-T depression and $\mathrm{T}$ wave inversion in leads I and CR7, but one 2L 
showed the changes in leads II, III, and CR7 and none in lead I, a pattern of left ventricular preponderance of aortic valve disease. It is well recognized that changes of left ventricular preponderance may mask ischæmic changes in the cardiogram. This is illustrated by a man, aged 66 , with cardiac pain and aortic incompetence. The cardiogram showed left ventricular preponderance on four occasions, although once there was a flattening of the S-T segment in lead CR4, which might signify the presence of ischæmia (Fig. 6).

This patient died and necropsy showed considerable stenosis of the orifice of the right coronary artery from syphilitic aortitis. The myocardium of the left ventricle which was hypertrophied, showed scattered small areas of fibrosis with one larger area in the posterior wall. There was incidental moderate atheroma of the coronary arteries.

\section{Changes in Rhythm}

Four cases showed bundle-branch block, three of the right branch and one of the left; this last was transient and at another time showed left ventricular preponderance only.

Two patients had a prolonged $P-R$ period, one of them later developing auricular fibrillation. A third patient had a nodal rhythm. Auricular fibrillation was seen in four, one of these had previously had a prolonged P-R period. A normal cardiogram was seen in 22 patients.

\section{Cardiac Pain}

Cardiac pain was present in 34 patients. In 30 it was induced by physical exertion especially walking, and was relieved by rest although sometimes it would occur at night and last for a time. Excitement, dreaming, and bending would sometimes precipitate attacks of pain. In the remaining four, periodic attacks of long duration as in cardiac infarction had not been associated with shorter attacks during effort.

The electrocardiogram was abnormal in 33 patients : 19 had ischæmic effects, 8 had left ventricular preponderance, 6 had left ventricular preponderance and ischæmia, and 2 had bundlebranch block. In the remaining one the tracing was normal and showed no change after exercise. This patient had typical cardiac pain 16 years previously, remained free from pain for 15 years following antiluetic treatment. This suggested that there had been a halting of the pathological process in her case.

Pain that was not accepted as anginal was present in 21 cases and in 10 of these it was thought to be unconnected with the heart condition. In eight it was related to the presence of an aneurysm, and in two it was paroxysmal, but was atypical of cardiac pain in that it was not induced by exertion. These two had nocturnal pain, particularly related to nocturnal dyspnœa and were among the eight showing left ventricular preponderance only. One of them had nocturnal pain, with left ventricular failure, but as soon as this was relieved by treatment the pain ceased. The other patient died and necropsy showed no coronary artery obstruction, confirming the wisdom of the decision to exclude such cases from the group with anginal pain. This patient experienced pain in the left shoulder for three years, unrelated to exertion but for two months before he died he complained of burning pain across the chest, coming only at night and usually related to nocturnal dyspnœa, although sometimes occurring apart from it. His cardiogram showed left ventricular preponderance with prolonged $\mathbf{P}-\mathbf{R}$ interval at first, while later auricular fibrillation developed. At necropsy there was no involvement of the coronary orifices by the syphilitic aortitis nor of the arteries themselves from atheroma as shown by the injection of opaque material. The myocardium showed some small areas of patchy fibrosis involving the atria as well as the ventricles. There was no explanation for the auricular fibrillation. The presence of fibrosis was not easily explained, but might have been the result of the large size of the heart, with a relatively inadequate coronary circulation; the fibrotic stage of syphilitic myocarditis was a possible explanation, but microscopically the lesions did not suggest this. The pain appeared to be related to left ventricular failure. There were 11 patients with normal cardiograms in this group. One patient had a nodal rhythm and another a right bundle-branch block.

There were no cases with cardiographic changes indisputably the outcome of cardiac ischæmia 
among 18 patients without pain. Ten had normal tracings. One had right bundle-branch block. Five had left ventricular preponderance in the presence of aortic incompetence; one of these also had auricular fibrillation. Two had auricular fibrillation without other abnormalities except the effects of digitalis.

\section{The Changes in the Myocardium in Aortitis}

To investigate the changes in the myocardium that explained the cardiographic changes, the post-mortem records of the Bernhard Baron Institute of Pathology at the London Hospital were consulted for the years 1922 to 1948 . There were 180 cases of syphilitic aortitis. In 73 there was stenosis of one or both coronary orifices; 42 of these had changes in the myocardium on naked eye examination and in 31 the changes appeared to have been caused by stenosis of the coronary orifices from syphilitic aortitis, for coronary atheroma was not once severe. In fact, where the ostial stenosis from aortitis was severe, the amount of coronary atheroma was usually slight. In the remaining 11 cases showing microscopical changes in the myocardium, there were 5 with severe atheroma, one with a gumma, one with a small dilated blood space in the myocardium, and four without coronary involvement. In microscopic sections of these four there was no conspicuous evidence that the fibrosis was due to syphilitic myocarditis. The fibrosis was dense, like old scar tissue, and cells were few. It was found impossible to decide whether it was ischæmic or inflammatory.

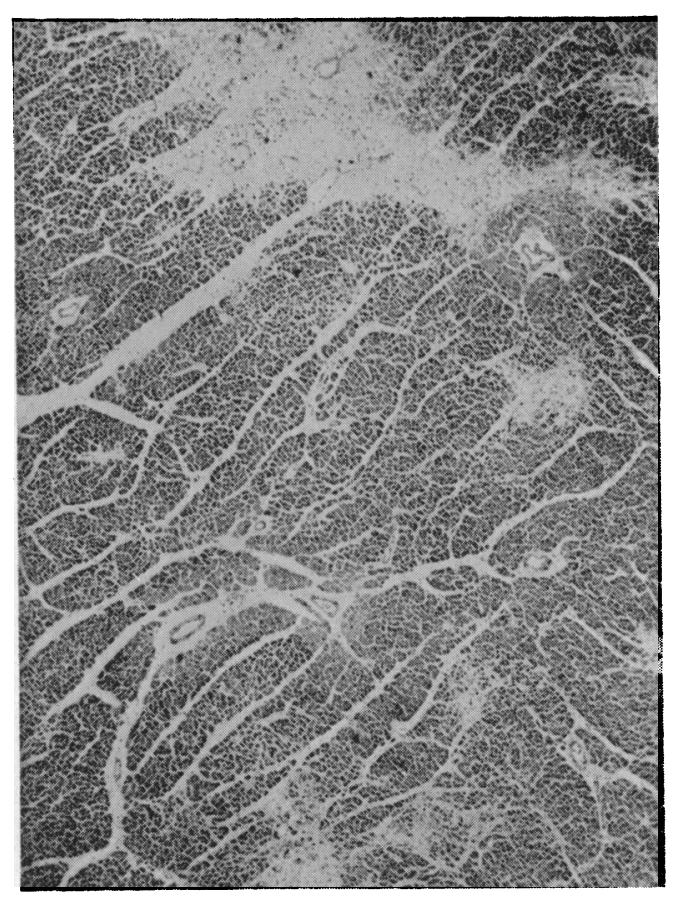

FIG. 7.-Patchy fibrosis in the myocardium (left ventricle) P.M. 47/42. $\mathrm{H}$ and E. Mag. $\times 21$.

In the 31 cases myocardial fibrosis was most commonly found as small patches scattered throughout the left ventricle (Fig. 7). In some cases there were larger patches, found most frequently in the interventricular septum and in the posterior wall of the left ventricle. The papillary muscles of the mitral valve were also commonly affected. These areas of fibrosis were often subendocardial (Fig. 8) and in three they were very extensive: one involved the left half of the posterior wall, fading off in the upper part and affecting the whole circumference at the apex; in another an area of fibrosis about $0.2 \mathrm{~cm}$. thick involved the whole 


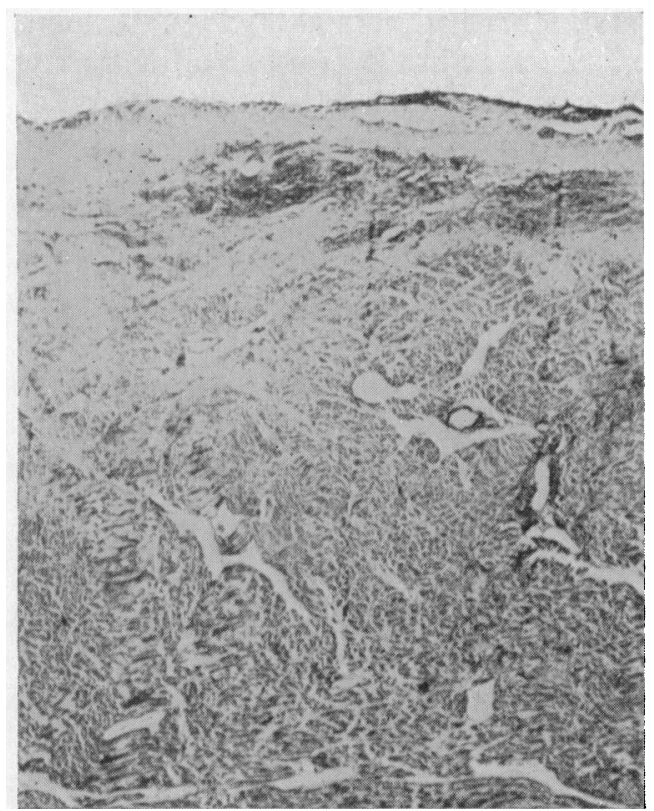

FIG. 8.-Subendocardial fibrosis in the wall of the left ventricle. Van Gieson. Mag. $\times 19$.

subendocardial region of the left ventricle, and was most severe in the posterior wall and posterior part of the interventricular septum: in a third case there was a very thin area of subendocardial fibrosis in the posterior papillary muscles of the mitral valve. The large size of these areas suggest that they might represent the fibrotic stage of formerly acute cardiac infarction, but between the fibrosis and the normal subpericardial muscle there were areas of muscle fibres with poorly staining nuclei suggesting slow degeneration, and some multinucleate muscle fibres suggesting regeneration.

These features indicate a gradual ischæmic atrophy rather than the fibrotic stage of acute infarction. In one case there was a large area of necrosis; this, though somewhat patchy and ill-defined, involved an area that measured $12 \times 9 \mathrm{~cm}$. in the anterior part of the interventricular septum. From its microscopical appearance the infarction was judged to be three to four days old. In the region of this recent infarction there was also slight evidence of old ischæmic atrophy in the form of a few small areas of fibrosis and vacuolation of the muscle fibres immediately under the endocardium. In another case there was a small recent infarct in the posterior wall of the left ventricle. In yet another there were very small areas of recent infarction related to areas of ischæmic atrophy.

Thus, there were three main effects of cardiac ischæmia from luetic stenosis of the coronary orifices. First, small patches of fibrosis scattered throughout the left ventricle probably the result of gradual ischæmia and rarely associated with small areas of recent infarction: this was the commonest change. Secondly, there were large areas of subendocardial fibrosis, either the result of recent infarction or more likely of gradual ischæmia. Thirdly, and rarely, large areas of recent infarction were present.

\section{DisCUSSION}

The findings in this series regarding the relation of cardiac pain and the cardiogram are at variance with those of other authors (Smith and Blackford, 1938; Burch and Winsor, 1942). Thus, in this series 33 out of 34 cases with cardiac pain showed abnormal tracings, whereas only 17 out of 38 were abnormal among those with no pain or non-cardiac pain in the chest. This may be due to difference in criteria of normality or to the use of an increased number of chest leads, but may also be due to the fact that previous writers have not differentiated cardiac pain from non-cardiac 
pain. Even so, there is a difference between the findings in those with pain in the chest of any sort (42 out of 54 abnormal) and those with no pain ( 8 out of 18 abnormal). Nevertheless, although the cardiogram is abnormal in a high percentage of cases with cardiac pain, positive evidence of cardiac ischæmia is often difficult to obtain; this is attributable first to the rarity of abnormal $\mathrm{Q}$ waves in the tracings (only 2 cases in this series) and secondly to the frequent presence of left ventricular preponderance from aortic incompetence.

The rarity of large areas of infarction post mortem in syphilitic heart disease, as noted by previous authors (Burch and Winsor, 1942; Cole and Bohring, 1944), is confirmed in this series: only one example among 180 cases of syphilitic heart disease was found on critical examination of the post-mortem records.

The presence of S-T depression indicating lesser myocardial changes may be difficult to distinguish in the presence of left ventricular preponderance on a single tracing. The shape of the S-T and T waves, regarded by Parsonnet and Bernstein (1943) as important, is not always reliable, but a changeability of the tracing may be a valuable aid to diagnosis if other factors that cause alteration in the cardiogram can be ruled out. Thus, nine cases in this series showed this changeable cardiogram. None of these had heart failure, none gave a history of paroxysmal tachycardia, and none was receiving digitalis or arsenic; one was taking penicillin, while others were having iodine and mercury or bismuth. There did not seem to be any evidence to incriminate these drugs.

Katz (1946) has noted the changing cardiogram in syphilitic heart disease relating it to transient coronary insufficiency, using Masters terminology. The electrocardiographic and pathological findings in this series may be similar to those described by Master et al. (1944) as characteristic of coronary insufficiency. The variation in the cardiogram and the absence of $Q$ waves have been noted, and the pathological findings appear to be similar. The subendocardial region and the papillary muscles are mainly affected and the lesions are often of a patchy distribution: it is probable that these changes are due to slow ischæmia and to more abrupt episodes. Both types of lesion were found in this series and have been described by Love and Warner (1934) and Norris (1937).

The subendocardial localization of the lesions is attributed to the factors already discussed and left ventricular hypertrophy, being commonly present in syphilitic heart disease, is likely to be of particular importance. The S-T depression in the chest leads CR4-7 of the cardiogram are features both of left ventricular hypertrophy and of subendocardial ischæmia, and the presence of one may obscure the other.

The cases with cardiac pain and slight abnormalities in the cardiogram were investigated by the exercise test. Two of these gave positive tests and further experience may extend the use of this test, particularly if it can reveal ischæmia when the tracing already shows left ventricular preponderance. Bundle-branch block indicates myocardial changes if it involves the left branch and when there is only moderate aortic incompetence.

Auricular fibrillation has been said to be rare in syphilitic heart disease (Willius, 1930; Brenner, 1933), and in this series there were only four cases: one of them post mortem had no change other than syphilitic heart disease to account for the abnormal rhythm. In the other three the heart rate was slow and the patients were elderly. These features suggest that they were examples of lone fibrillation (Evans and Swann, 1954), rather than due to syphilitic heart disease. A-V dissociation has been reported in most series apart from gumma of the heart. A prolonged P-R interval in two cases was the only evidence in the present series of $\mathrm{A}-\mathrm{V}$ conduction defect, and one patient had nodal rhythm.

\section{SUMMARY}

The cardiograms of 72 cases of syphilitic heart disease were examined and the findings compared with those published by other authors.

The cardiograms were abnormal in 50 out of 72 patients and this was almost invariable in patients with cardiac pain (33 out of 34 cases).

Ischæmic changes are difficult to tell in the presence of left ventricular preponderance. The 
position of the fibrosis in the subendocardial region of the posterior wall of the left ventricle and in the interventricular septum adds another difficulty to the diagnosis of ischæmic changes in the cardiogram. A changing cardiogram was often the best evidence of ischæmia and was seen in 9 cases. Auricular fibrillation may result from syphilitic heart disease, although it is rare.

The presence of a large area of cardiac infarction was rare, and the changes in the myocardium usually indicated the presence of a more tardy process of limited extent in the form of ischæmic atrophy with replacement fibrosis, sometimes associated with small areas of recent necrosis. Such changes produce $T$ wave inversion in the electrocardiogram without $Q$ waves as a rule.

When syphilitic aortitis has been discovered or suspected the examination is incomplete if it does not include a cardiogram, for this often tells of involvement of the orifices of the coronary arteries by aortitis.

I wish to thank Dr. William Evans-physician to the department-for his advice and criticism, and I am grateful to Dr. W. Woods and Dr. J. F. Smith of the Bernhart-Baron Institute of Pathology for their advice on the pathological material.

\section{REFERENCES}

Annett, J. H. (1928). Amer. J. med. Sci., 176, 65.

Berk, L. H. (1941). N.Y. State J. Med., 41, 223.

Brenner, O. (1933). Birm. med. Rev., 8, 161.

Bruenn, H. G. (1934). Amer. Heart J., 9, 421.

Burch, G. E., and Winsor, T. (1942). Amer. Heart J., 24, 740.

Chamberiain, E. N., and Follows, J. (1933). Quart. J. Med., $2,221$.

Cole, S. L., and Bohring, A. (1944). Amer. J. med. Sci., 207, 317.

Cocmbs, C. F. (1932). Quart. J. Med., 25, 179.

Evans, W. (1948). Cardiology. Butterworth, London.

-, and McRae, C. (1952). Brit. Heart J., 14, 42.

, and Swann, P. (1954). Brit. Heart J., 16, 189.

Gallavardin, L. (1932). J. Méd. Lyon., 549.

Hall, D. (1932). Lancet, 1, 1254.

Heimann, H. L. (1927). Brit. med. J., 1, 133.

Ingraham, R., and Maynard, E. P. (1930). Amer. Heart J., 6, 82.

Jones, E., and Bedford, D. E. (1943). Brit. Heart J., 5, 107.

Juster, I. R. Pardee, H. E. B. (1929). Amer. Heart J., 5, 84.

Katz, L. N. (1946). Electrocardiography. 2nd ed., London, p. 435.

Klotz, S. D., and Crede, R. H. (1945). Amer. Heart J., 30, 551.

Love, W. S., and Warner, G. C. (1934). Amer. J. Syph., 16, 154.

Levine, H. D., and Ford, R. V. (1950). Circulation, 1, 246.

Master, A. M., Jaffe, H. L., Dack, S., and Grishman, A. (1944). Amer. Heart J., $27,803$.

Norris, J. C. (1937). J. Amer. med. Ass., 108, 169.

Parkinson, J., and Bedford, D. E. (1931). Lancet, 1, 15.

Parsonnet, A. E., and Bernstein, A. (1943). Unolog. Cut. Rev., 47, 516.

Smith, C., and Blackford, L. M. (1938). Amer. J. Syph., 22, 168.

Sprague, H. B. (1942). J. Mt. Sinai Hosp., 8, 1034.

Turner, K. B., and White, P. D. (1927). Arch. intern. Med., 39, 1.

Willius, F. A. (1930). Amer. Heart J., 6, 113.

Yu, P. N. G., and Stewart, J. (1950). Amer. Heart J., 39, 862. 